\title{
Effects of Curcuma Drugs on Vasomotion in Isolated Rat Aorta
}

\author{
Yohei Sasaki, ${ }^{a}$ Hirozo Goto, ${ }^{b}$ Chihiro Tohda, ${ }^{a}$ Fumiyuki Hatanaka, ${ }^{a}$ Naotoshi Shibahara, ${ }^{b}$ \\ Yutaka Shimada, ${ }^{c}$ Katsutoshi Terasawa, ${ }^{c}$ and Katsuko Komatsu ${ }^{*, a}$ \\ ${ }^{a}$ Research Center for Ethnomedicines, Institute of Natural Medicine, Toyama Medical and Pharmaceutical University; \\ ${ }^{b}$ Department of Kampo Diagnostics, Institute of Natural Medicine, Toyama Medical and Pharmaceutical University; and \\ ${ }^{c}$ Department of Japanese Oriental Medicine, Faculty of Medicine, Toyama Medical and Pharmaceutical University; 2630 \\ Sugitani, Toyama 930-0194, Japan. Received December 11, 2002; accepted April 4, 2003
}

The effectiveness of Curcuma drugs against "Oketsu" and the differences in their efficacy were evaluated by examining their vasomotional effects as one index. Since nitric oxide (NO) is the relaxation factor of vascular smooth muscle and also an inhibitor of platelet aggregation in blood vessels, substances showing NO-dependent relaxation are thought to be effective in improving Oketsu. In this study, five Curcuma drugs derived from $C u r-$ cuma longa, $C$. kwangsiensis, $C$. phaeocaulis, $C$. wenyujin, and $C$. zedoaria were used. Methanol extracts exhibited intense effects on relaxation in rings precontracted by prostaglandin $F_{2 \alpha}\left(P_{G F}\right)$ despite pretreatment with and without $N^{\mathrm{G}}$-nitro-l-arginine methyl ester (L-NAME) as an inhibitor of NO synthesis. The maximal activities were approximately $80 \%$ at $10^{-3} \mathrm{~g} / \mathrm{ml}$. From these methanol extracts, curcumin and eight sesquiterpenes were isolated. Since all these compounds showed NO-independent relaxation effects with almost the same intensities, the relaxation effects of Curcuma drugs can be estimated by the total amounts of curcumin and sesquiterpenes. Polysaccharides, the main constituents of methanol-insoluble compounds of water extracts, in contrast, showed contraction effects; only polysaccharides in $C$. zedoaria showed NO-dependent relaxation as well as contraction. All water extracts showed relaxation effects as sum of the methanol-soluble compounds-induced relaxation and polysaccharides-induced contraction. Therefore, all Curcuma drugs tested in the present study can be effective for vasodilation. Moreover, the drug derived from $C$. zedoaria has potential to cure Oketsu with its various acting points.

Key words Curcuma drug; Oketsu; nitric oxide; vasomotional effect; sesquiterpene; curcumin

There are many reports on the pharmacological effects of Curcuma drugs such as their antitumor, ${ }^{1)}$ anti-inflammatory, ${ }^{2)}$ and immunological activities. ${ }^{3)}$ Traditionally, Curcuma drugs have been used for "Oketsu" (various syndromes caused by the obstruction of blood circulation such as arthralgia, psychataxia and dysmenorrhea) in the system of Chinese medicine. In Chinese herbal literature, Ben-cao gang-mu (本草綱 目 $)^{4)}$ in 1596 , “Yujin (郁金)" enters the heart to control blood circulation, “Jianghuang (姜黄)" enters the spleen to assist in the stomach function and to promote Qi (気), and "Ezhu (莪 术)” enters the liver to eliminate blood stasis. Although these drugs used to be thought to have different effects, it is doubtful whether the botanical origins of drugs with these names correspond to those of present day drugs with the same names. Since ancient times, especially for Curcuma drugs, it has been difficult to identify the botanical origins, because Curcuma plants and drugs are similar in morphology and the naming of drugs has varied, depending on the portion used or the producing area in addition to the botanical origin. Nowadays, four Curcuma drugs are prescribed in Chinese Pharmacopoeia; Yujin (郁金, the tubers of Curcuma wenyujin, $C$. longa, C. kwangsiensis or C. phaeocaulis) is said to promote circulation of Qi and eliminate stagnant blood; Jianghuang (姜黄, the rhizome of C. longa) and Pian-Jianghuang (片姜 黄, the rhizome of $C$. wenyujin) are said to improve blood stasis and promote the circulation of Qi; and Ezhu (莪术, the rhizomes of $C$. phaeocaulis, C. kwangsiensis or C. wenyujin) is said to promote circulation of Qi and improve blood stasis. Curcuma drugs cannot be simply classified by botanical origin, and differences in the effects among different Curcuma drugs are not obvious.

Oketsu is one of the pathophysiological concepts in Kampo medicine. ${ }^{5)}$ Insufficient exercise or sleep, or mental or physical stress may cause stagnation of blood flow and lead to the Oketsu syndrome. Relaxation of blood vessels and fibrinolysis of blood are thought to result in improvement of the blood flow and are effective against Oketsu. Some Kampo prescriptions and their component drugs and chemical compounds were studied for their anti-Oketsu effect from the point of blood rheology ${ }^{5)}$ and vasodilation. ${ }^{6}$ Although basic research of Curcuma drugs for anti-Oketsu has not yet been done sufficiently, curcumin from C. longa was studied for anticoagulation of blood, ${ }^{7)}$ and dehydrocurdione from $C$. zedoaria was studied for relaxation of vascular smooth muscle. ${ }^{8)}$ In this study, we focused on vasomotional effects, especially on endothelial-dependent relaxation of the blood vessel as a key pathway for anti-Oketsu, because nitric oxide (NO) is one of the endothelium-derived relaxing factors (EDRF), ${ }^{9}$ and plays a role in inhibiting platelet aggregation in blood vessels. ${ }^{10)}$

We previously developed the ultimate method for identification of Chinese and Japanese Curcuma drugs by molecular biological analysis, ${ }^{11)}$ making it possible to use correctly identified Curcuma drugs. Our purpose was to learn whether these drugs are effective against Oketsu, and what the differences are in their efficacy. The vasomotional effects were examined on the isolated rat aorta.

\section{MATERIALS AND METHODS}

Materials Five Curcuma drugs which were correctly identified by the molecular biological method previously reported, ${ }^{11)}$ were used in this study. Ukon (derived from $C$. longa; Guangdong, China), Gajutsu (revealed by the molecular biological method to be a mixture of $C$. kwangsiensis and C. phaeocaulis; Guangxi, China), Gajutsu (C. phaeocaulis; 
Sichuan, China), Henkyouou (C. wenyujin; Zhejiang, China), and Gajutsu (C. zedoaria; Okinawa, Japan) (Table 1). In the following manuscript, the materials are referred to by the original plant names (abbreviations of scientific names) of the crude drugs. All drugs are stored in the Museum of Materia Medica, Institute of Natural Medicine, Toyama Medical and Pharmaceutical University (TMPW), Japan.

Chemical Reagent $N^{\mathrm{G}}$-Nitro-l-arginine methyl ester (LNAME) was purchased from Sigma Chemicals. Prostaglandin $\mathrm{F}_{2 \alpha}\left(\mathrm{PGF}_{2 \alpha}\right)$ and acetylcholine chloride were purchased from Wako Chemicals.

General Equipment Silica gel column chromatography $\left(\mathrm{SiO}_{2} \mathrm{CC}\right)$ was conducted with Wakogel C-300 (Wako) and preparative HPLC was performed on a JASCO 1500 series (PU-1587 and UV-1575) with a column YMC-Pack ODS-A (YMC, $250 \mathrm{~mm} \times 20 \mathrm{~mm}$ I.D. $5 \mu \mathrm{m}$ ). NMR spectra were measured in chloroform- $d_{1}$ solution with tetramethylsilane as the internal standard on a JEOL JNM-LA-400 $\left(400 \mathrm{MHz}\right.$ for ${ }^{1} \mathrm{H}$, $100 \mathrm{MHz}$ for ${ }^{13} \mathrm{C}$ ) spectrometer. Mass spectra (MS) were measured on a JEOL JMS-GC mate GCMS SYSTEM (EIMS).

Sample Preparation The water extracts were prepared as follows. One hundred grams of powdered each drug was refluxed in 11 of $\mathrm{H}_{2} \mathrm{O}$ for $2 \mathrm{~h}$. After cooling down to room temperature, the solution was centrifuged at $1200 \boldsymbol{g}$ for $15 \mathrm{~min}$, filtered and freeze-dried into a resultant powder. The methanol extracts were prepared as follows. One hundred grams of powdered drug was placed in methanol $(11 \times 2)$ for $12 \mathrm{~h}$ at room temperature. The combined supernatants were evaporated to obtain the methanol extracts. The polysaccharides were prepared from $50 \mathrm{~g}$ of residue of the methanol extraction and refluxed in 11 of $\mathrm{H}_{2} \mathrm{O}$ for $2 \mathrm{~h}$. After cooling down to room temperature, the solution was centrifuged at $1200 \mathrm{~g}$ for $15 \mathrm{~min}$, and purified by ethanol precipitation method (9 volumes of ethanol). Only the extract of C. longa (CL) was purified two times, because it contained many lipophilic compounds. The precipitate was dissolved in water and freeze-dried into whitish powder (Chart 1). The yields of extracts and polysaccharides are listed in Table 1. For the present experiments, water extracts and polysaccharides were dissolved in distilled water, and methanol extracts in dimethyl sulfoxide (DMSO).

Isolation of the Compounds from Curcuma Drugs From $500 \mathrm{~g}$ of $\mathrm{CL}$ and each $1000 \mathrm{~g}$ of mixed sample of $C$. kwangsiensis and C. phaeocaulis (CKP), C. phaeocaulis (CP), C. wenyujin (CW) and C. zedoaria (CZ), methanol extracts were prepared in yields of $13,4,7,15$ and $5 \%$, respectively. These extracts were partitioned with hexane and water and then with ethyl acetate and water. Curcumin was isolated from the ethyl acetate layer of CL. From the hexane layer of $\mathrm{CL}, a r$-turmerone, $\alpha$-turmerone, and $\beta$-turmerone were isolated by successive $\mathrm{SiO}_{2} \mathrm{CC}$ and recycling preparative HPLC. When $\alpha$-turmerone and $\beta$-turmerone were tested, a mixture of the two was used in the experiments because they were difficult to separate from each other. Their ratio was estimated to be $5: 4$ ( $\alpha$-turmerone: $\beta$-turmerone) from ${ }^{1} \mathrm{H}$ NMR. In the same way, from the hexane layer furanodiene was isolated from CKP, furanodienone from CP, curdione and germacrone from $\mathrm{CW}$, and dehydrocurdione from $\mathrm{CZ}$, respectively (Chart 1).

Spectral Data $a r$-Turmerone ${ }^{12)}: \mathrm{MS}: m / z 216\left(\mathrm{M}^{+}\right) .{ }^{1} \mathrm{H}-$

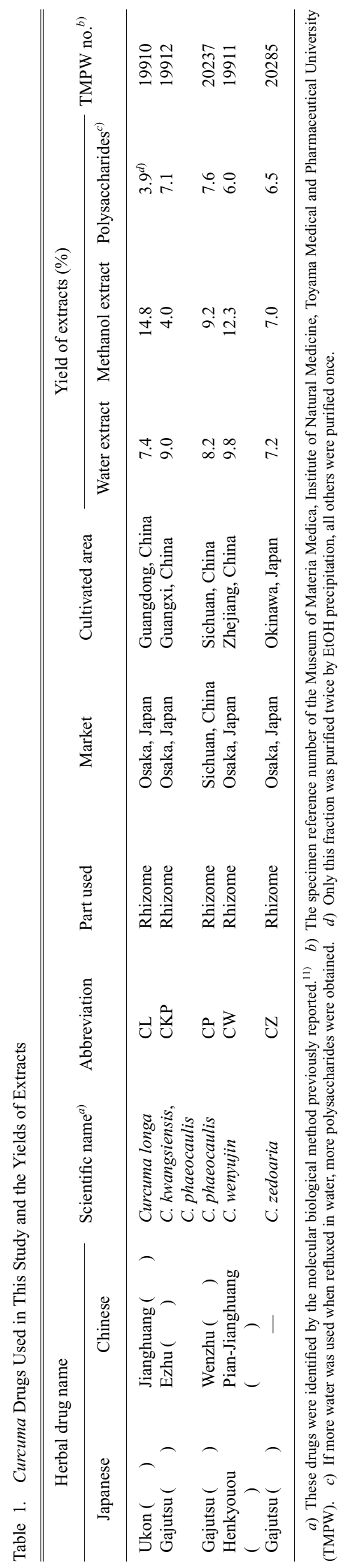




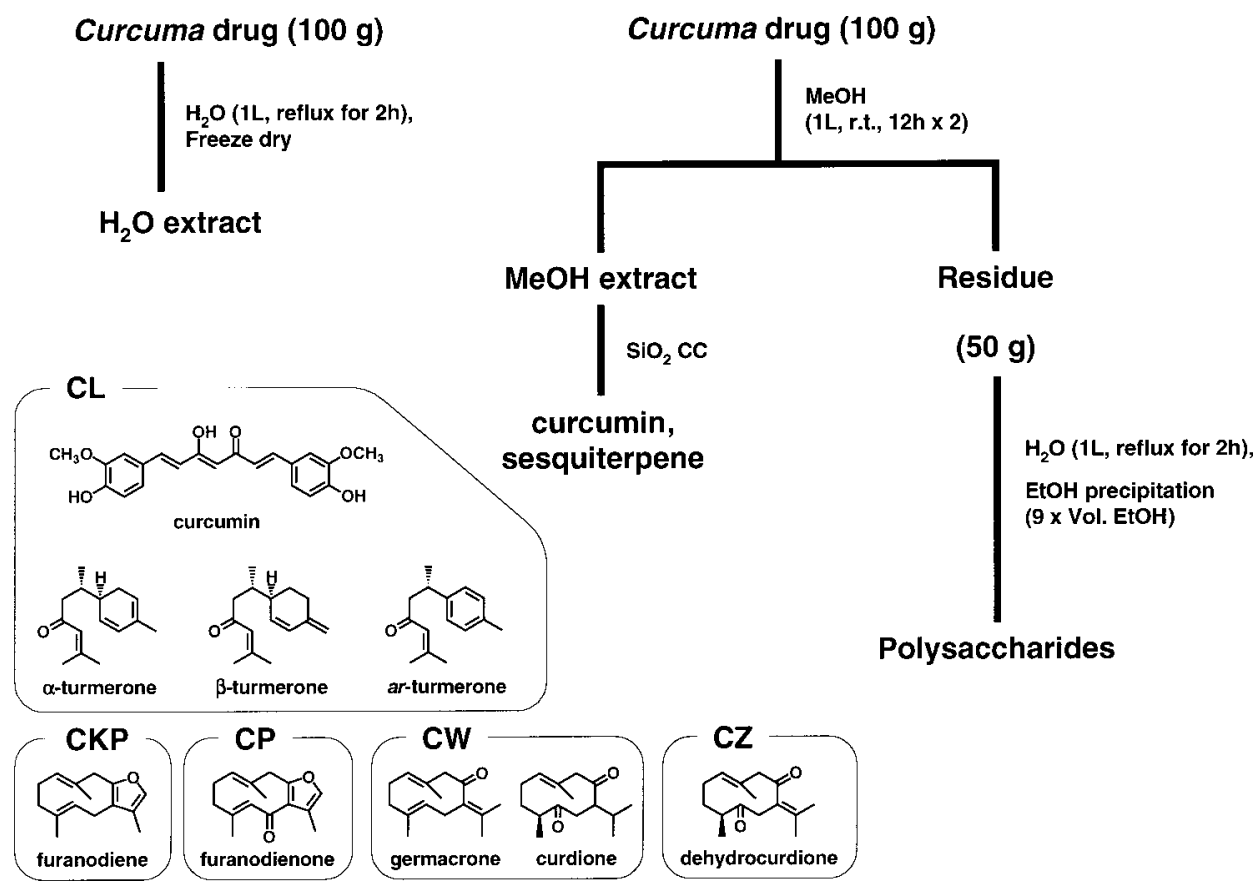

Chart 1. Sample Preparations and Compounds Isolated from Curcuma Drugs Abbreviations same as in Fig. 1.

NMR $\left(\mathrm{CDCl}_{3}\right) \delta ; 7.10(4 \mathrm{H}$, brd, $J=1.7 \mathrm{~Hz}), 6.02(1 \mathrm{H}, \mathrm{t}$, $J=1.2 \mathrm{~Hz}), 3.28(1 \mathrm{H}, \mathrm{ddd}, J=8.4,6.7,6.0 \mathrm{~Hz}), 2.68(1 \mathrm{H}, \mathrm{dd}$, $J=15.7,6.0 \mathrm{~Hz}), 2.60(1 \mathrm{H}, \mathrm{dd}, J=15.7,8.4 \mathrm{~Hz}), 2.30(3 \mathrm{H}, \mathrm{s})$, $2.10(3 \mathrm{H}, \mathrm{d}, J=1.2 \mathrm{~Hz}), 1.85(3 \mathrm{H}, \mathrm{d}, J=1.2 \mathrm{~Hz}), 1.24(3 \mathrm{H}, \mathrm{d}$, $J=6.7 \mathrm{~Hz}$ ).

$\alpha$-Turmerone ${ }^{13)}$ : MS: $m / z 218\left(\mathrm{M}^{+}\right) .{ }^{1} \mathrm{H}-\mathrm{NMR}\left(\mathrm{CDCl}_{3}\right) \delta$; $6.06(1 \mathrm{H}, \mathrm{t}, J=1.3 \mathrm{~Hz}), 5.80(1 \mathrm{H}, \mathrm{ddd}, J=9.6,1.9,1.7 \mathrm{~Hz})$, $5.64(1 \mathrm{H}, \mathrm{dd}, J=9.6,3.1 \mathrm{~Hz}), 5.43(1 \mathrm{H}, \mathrm{br} \mathrm{s}), 2.50(1 \mathrm{H}, \mathrm{dd}$, $J=14.5,3.9 \mathrm{~Hz}), 2.3-2.0(5 \mathrm{H}, \mathrm{m}), 2.14(3 \mathrm{H}, \mathrm{d}, J=1.3 \mathrm{~Hz})$, $1.88(3 \mathrm{H}, \mathrm{d}, J=1.3 \mathrm{~Hz}), 1.71(3 \mathrm{H}, \mathrm{d}, J=1.7 \mathrm{~Hz}), 0.89(3 \mathrm{H}, \mathrm{d}$, $J=6.5 \mathrm{~Hz}$ ).

$\beta$-Turmerone ${ }^{13)}$ : MS: $m / z 218\left(\mathrm{M}^{+}\right) .{ }^{1} \mathrm{H}-\mathrm{NMR}\left(\mathrm{CDCl}_{3}\right) \delta$; $6.16(1 \mathrm{H}, \mathrm{dd}, J=10.0,2.3 \mathrm{~Hz}), 6.07(1 \mathrm{H}, \mathrm{dd}, J=1.2,1.0 \mathrm{~Hz})$, $5.67(1 \mathrm{H}$, br d, $J=10.7 \mathrm{~Hz}), 4.77(1 \mathrm{H}, \mathrm{br} \mathrm{s}), 4.75(1 \mathrm{H}, \mathrm{br} \mathrm{s})$, $2.50-2.40(2 \mathrm{H}, \mathrm{m}), 2.35-2.15(3 \mathrm{H}, \mathrm{m}), 2.14(3 \mathrm{H}, \mathrm{d}$, $J=1.0 \mathrm{~Hz}), 2.03(1 \mathrm{H}, \mathrm{m}), 1.88(3 \mathrm{H}, \mathrm{d}, J=1.2 \mathrm{~Hz}), 1.64(1 \mathrm{H}$, m), $1.38(1 \mathrm{H}, \mathrm{m}), 0.88(3 \mathrm{H}, \mathrm{d}, J=6.3 \mathrm{~Hz})$.

Curcumin $^{14)}$ : MS: $m / z 368\left(\mathrm{M}^{+}\right) .{ }^{1} \mathrm{H}-\mathrm{NMR}\left(\mathrm{CDCl}_{3}\right) \delta$; $7.59(2 \mathrm{H}, \mathrm{d}, J=15.7 \mathrm{~Hz}), 7.12(2 \mathrm{H}, \mathrm{dd}, J=8.2,2.0 \mathrm{~Hz}), 7.05$ $(2 \mathrm{H}, \mathrm{d}, J=1.7 \mathrm{~Hz}), 6.93(2 \mathrm{H}, \mathrm{d}, J=8.2 \mathrm{~Hz}), 6.48(2 \mathrm{H}, \mathrm{d}$, $J=15.7 \mathrm{~Hz}), 5.80(1 \mathrm{H}, \mathrm{s}), 3.95(6 \mathrm{H}, \mathrm{s})$.

Furanodiene ${ }^{15)}$ : MS: $m / z 216\left(\mathrm{M}^{+}\right) .{ }^{1} \mathrm{H}-\mathrm{NMR}\left(\mathrm{CDCl}_{3}\right) \delta$; $7.06(1 \mathrm{H}, \mathrm{s}), 4.93(1 \mathrm{H}, \mathrm{dd}, J=10.8,5.3 \mathrm{~Hz}), 4.73(1 \mathrm{H}, \mathrm{t}$, $J=7.0 \mathrm{~Hz}), 3.53(1 \mathrm{H}, \mathrm{d}, J=15.6 \mathrm{~Hz}), 3.42(1 \mathrm{H}, \mathrm{d}, J=$ $15.6 \mathrm{~Hz}), 3.07(2 \mathrm{H}, \mathrm{d}, J=7.0 \mathrm{~Hz}), 2.23(1 \mathrm{H}, \mathrm{td}, J=12.0$, $3.3 \mathrm{~Hz}), 2.18-1.03(2 \mathrm{H}, \mathrm{m}), 1.91(3 \mathrm{H}, \mathrm{d}, J=1.2 \mathrm{~Hz}), 1.77$ $(1 \mathrm{H}, \mathrm{td}, J=11.6,5.3 \mathrm{~Hz}), 1.59(3 \mathrm{H}, \mathrm{s}), 1.26(3 \mathrm{H}, \mathrm{s})$.

Furanodienone ${ }^{16)}$ : MS: $m / z 230\left(\mathrm{M}^{+}\right) .{ }^{1} \mathrm{H}-\mathrm{NMR}\left(\mathrm{CDCl}_{3}\right)$ $\delta ; 7.07(1 \mathrm{H}, \mathrm{s}), 5.81(1 \mathrm{H}, \mathrm{s}), 5.18(1 \mathrm{H}, \mathrm{dd}, J=11.6,4.8 \mathrm{~Hz})$, $3.70(2 \mathrm{H}, \mathrm{s}), 2.47(1 \mathrm{H}$, ddd, $J=11.3,4.0,3.4 \mathrm{~Hz}), 2.32(1 \mathrm{H}$, dddd, $J=12.0,4.8,4.4,4.0 \mathrm{~Hz}), 2.18$ (1H, dddd, $J=12.3$, 12.0, 11.6, 3.4 Hz), $2.13(3 \mathrm{H}, \mathrm{s}), 1.99(3 \mathrm{H}, \mathrm{s}), 1.88(1 \mathrm{H}, \mathrm{ddd}$, $J=12.3,11.3,4.4 \mathrm{~Hz}), 1.30(3 \mathrm{H}, \mathrm{s})$.

Curdione ${ }^{17,18)}$ : MS: $m / z 236\left(\mathrm{M}^{+}\right) .{ }^{1} \mathrm{H}-\mathrm{NMR}\left(\mathrm{CDCl}_{3}\right) \delta$; $5.17(1 \mathrm{H}, \mathrm{brs}), 3.65(1 \mathrm{H}, \mathrm{d}, J=11.0 \mathrm{~Hz}), 2.94(1 \mathrm{H}, \mathrm{d}$,
$J=11.0 \mathrm{~Hz}), 2.85(1 \mathrm{H}, \mathrm{ddd}, J=2.2,8.8,8.8 \mathrm{~Hz}), 2.70(1 \mathrm{H}$, $\mathrm{dd}, J=16.7,8.8 \mathrm{~Hz}), 2.40(1 \mathrm{H}, \mathrm{dd}, J=16.7,2.2 \mathrm{~Hz}), 2.30-$ $2.32(1 \mathrm{H}, \mathrm{m}), 2.05-2.20(3 \mathrm{H}, \mathrm{m}), 1.87(1 \mathrm{H}, \mathrm{m}), 1.66(3 \mathrm{H}$, s), $1.54-1.60(1 \mathrm{H}, \mathrm{m}), 0.98(3 \mathrm{H}, \mathrm{d}, 7.0 \mathrm{~Hz}), 0.95(3 \mathrm{H}, \mathrm{d}$, $J=6.8 \mathrm{~Hz}), 0.89(3 \mathrm{H}, \mathrm{d}, J=6.5 \mathrm{~Hz}) .{ }^{13} \mathrm{C}-\mathrm{NMR}\left(\mathrm{CDCl}_{3}\right) \delta$; 214.3, 211.1, 131.5, 129.8, 55.8, 53.5, 46.7, 44.2, 34.0, 29.9, $26.4,21.1,19.8,18.5,16.5$.

Germacrone ${ }^{19)}$ : MS: $m / z 218\left(\mathrm{M}^{+}\right) .{ }^{1} \mathrm{H}-\mathrm{NMR}\left(\mathrm{CDCl}_{3}\right) \delta$; $4.96(1 \mathrm{H}, \mathrm{d}, J=11.8 \mathrm{~Hz}), 4.68(1 \mathrm{H}, \mathrm{d}, J=10.4 \mathrm{~Hz}), 3.38(1 \mathrm{H}$, d, $J=10.4 \mathrm{~Hz}), 2.94(1 \mathrm{H}, \mathrm{d}, J=10.4 \mathrm{~Hz}), 2.94(1 \mathrm{H}, \mathrm{d}$, $J=13.5 \mathrm{~Hz}), 2.83(1 \mathrm{H}, \mathrm{d}, J=13.5 \mathrm{~Hz}), 2.34(1 \mathrm{H}, \mathrm{m}), 2.18$ $2.00(3 \mathrm{H}, \mathrm{m}), 1.75(3 \mathrm{H}, \mathrm{s}), 1.70(3 \mathrm{H}, \mathrm{s}), 1.60(3 \mathrm{H}, \mathrm{s}), 1.41$ $(3 \mathrm{H}, \mathrm{s})$.

Dehydrocurdione ${ }^{20)}$ : MS: $m / z 234\left(\mathrm{M}^{+}\right) .{ }^{1} \mathrm{H}-\mathrm{NMR}\left(\mathrm{CDCl}_{3}\right)$ $\delta$; $5.16(1 \mathrm{H}, \mathrm{brs}), 3.30(1 \mathrm{H}, \mathrm{d}, J=16.5 \mathrm{~Hz}), 3.24(1 \mathrm{H}, \mathrm{d}$, $J=11.4 \mathrm{~Hz}), \quad 3.22(1 \mathrm{H}, \quad \mathrm{d}, \quad J=16.5 \mathrm{~Hz}), 3.07 \quad(1 \mathrm{H}, \quad \mathrm{d}$, $J=11.4 \mathrm{~Hz}), 2.41(1 \mathrm{H}, \mathrm{m}), 2.20-2.00(3 \mathrm{H}, \mathrm{m}), 1.78(3 \mathrm{H}, \mathrm{s})$, $1.75(3 \mathrm{H}, \mathrm{s}), 1.70-1.65(1 \mathrm{H}, \mathrm{m}), 1.65(3 \mathrm{H}, \mathrm{br} \mathrm{s}), 1.02(3 \mathrm{H}$, d, $J=7.1 \mathrm{~Hz}$ ).

Experiments of Vasomotional Effect ${ }^{21)}$ Male Wistar rats weighing $350-450 \mathrm{~g}$ were anesthetized by nembutal (50 mg/kg i.p.) and sacrificed by cutting their abdominal aorta. A section of the thoracic aorta was carefully cleaned of fat and connective tissues, and cut into $3 \mathrm{~mm}$ length. The rings were mounted on steel hooks in a Magnus chamber (Kishimoto UC-5TD, Kyoto). One end of the aorta was attached to a force-displacement transducer (Kishimoto UM203) so that its isometric contraction could be recorded (Niko Bioscience T-634, Tokyo). Baths were filled with $5 \mathrm{ml}$ of Krebs solution consisting of (mM): $\mathrm{NaCl} 120.0, \mathrm{KCl} 4.7$, $\mathrm{NaHCO}_{3} 25.0, \mathrm{KH}_{2} \mathrm{PO}_{4} 1.2, \mathrm{MgSO}_{4} \cdot 7 \mathrm{H}_{2} \mathrm{O} 1.2, \mathrm{CaCl}_{2} 2.5$ and glucose 10.0. The solution was maintained at $37{ }^{\circ} \mathrm{C}$ and bubbled continuously with $5 \% \mathrm{CO}_{2}$ in $\mathrm{O}_{2}$ at $\mathrm{pH}$ of 7.4. The rings were equilibrated for $60 \mathrm{~min}$ at an initial resting tension of $1 \mathrm{~g}$, then contracted with $60 \mathrm{~mm} \mathrm{KCl}$ as the functional test. 
When contraction reached a steady maximal response, $10^{-6} \mathrm{M}$ acetylcholine chloride was added to confirm existence of the endothelium. The rings were regarded as intact when acetylcholine chloride exhibited $5-10 \%$ relaxation against $\mathrm{KCl}$-induced maximum contraction. The Krebs solution was replaced every $15 \mathrm{~min}$ for $60 \mathrm{~min}$ before the conduct of the experiments.

For relaxation experiments, each aortic strip was contracted by treatment with $6 \times 10^{-6} \mathrm{M} \mathrm{PGF}_{2 \alpha}$. When the $\mathrm{PGF}_{2 \alpha}$-induced contraction reached a plateau, test sample was cumulatively added at concentrations ranging from $10^{-6}$ to $10^{-3} \mathrm{~g} / \mathrm{ml}$ for water extracts, methanol extracts and polysaccharides, or from $10^{-7}$ to $10^{-4} \mathrm{M}$ for isolated compounds. Relaxation was expressed as percentage of the decrease in maximal tension obtained by $\mathrm{PGF}_{2 \alpha}$-induced contraction. To investigate the involvement of $\mathrm{NO}$, the ring preparations with the endothelium were exposed to $10^{-4} \mathrm{M}$ L-NAME, an inhibitor of NO synthesis, for $60 \mathrm{~min}$ before precontraction.

For contraction experiments, polysaccharides were cumulatively added to rings at concentrations ranging from $10^{-6}$ to $10^{-3} \mathrm{~g} / \mathrm{ml}$ without precontraction. Contraction was expressed as percentage of the increase from baseline when the maximal tension by $60 \mathrm{~mm} \mathrm{KCl}$ was regarded as $100 \%$. To determine the involvement of NO, the preparations with the endothelium were exposed to $10^{-4} \mathrm{M}$ L-NAME for $60 \mathrm{~min}$ before treatment with samples.

Statistical Analysis Statistical comparisons were made by Student's $t$-test or repeated measured two-way analysis of variance (ANOVA), and post hoc Student-Newman-Keuls multiple comparisons. $p<0.05$ was considered as significant. The means of data are represented together with S.E.M.

\section{RESULTS}

Vasomotional Effects of Water and Methanol Extracts, and Polysaccharides The water and methanol extracts prepared from the five Curcuma drugs were examined for vasomotion experiments on the rat aorta precontracted by $\mathrm{PGF}_{2 \alpha}$. These extracts were cumulatively added to the bath at concentrations from $10^{-6}$ to $10^{-3} \mathrm{~g} / \mathrm{ml}$. Typical tracings of the effects of the extracts are shown in Figs. 1 and 2. Relaxation was induced by treatment with each water extract at the concentration of $10^{-3} \mathrm{~g} / \mathrm{ml}$. The maximal activities were $65.3 \%$ in CL, $22.6 \%$ in CKP, $47.4 \%$ in CP, $54.4 \%$ in CW, and $38.3 \%$ in $\mathrm{CZ}$. For $\mathrm{CP}, \mathrm{CW}$, and $\mathrm{CZ}$, the rings were slightly contracted after relaxation, suggesting that these water extracts may contain components for contraction as well as relaxation (Fig. 1A). On the other hand, intense relaxation was evoked by treatment with each methanol extract. The activities at the concentration of $10^{-3} \mathrm{~g} / \mathrm{ml}$ were $78.6 \%$ in CL, $87.5 \%$ in CKP, $88.9 \%$ in CP, $86.2 \%$ in CW, and $85.8 \%$ in $\mathrm{CZ}$ (Fig. 2A). The concentration-response curves for water and methanol extracts are shown in Fig. 3. Only the water extract from $\mathrm{CP}$ was significantly different from vehicle at $3 \times 10^{-4} \mathrm{~g} / \mathrm{ml}$. At $10^{-3} \mathrm{~g} / \mathrm{ml}$, the relaxation activity was high in the order CL, CW, CP, CZ, and CKP (Fig. 3A). Except for CL, methanol extracts showed significant effects of relaxation at more than $10^{-4} \mathrm{~g} / \mathrm{ml}$. At $10^{-3} \mathrm{~g} / \mathrm{ml}$, no significant differences of relaxation activity were seen among the five Curcuma drugs (Fig. 3B). The ratios of methanol-soluble and -insoluble compounds in each water extract were investigated (Fig. 4). The percentage of methanol-soluble compounds in water extract was highest in CL (47.5\%) which showed the highest relaxation effect in Fig. 3A. The low content of methanol-soluble compounds was shown in CKP (14.3\%) and in CZ (10.5\%). Water extracts of these Curcuma drugs had lower relaxation effects compared with methanol extracts. The effects of polysaccharides were then tested, since they were isolated as the main components in methanol-insoluble residues. Unexpectedly, treatment with polysaccharides caused no relaxation but
A

CL

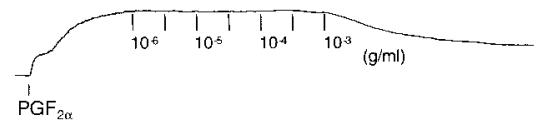

CKP

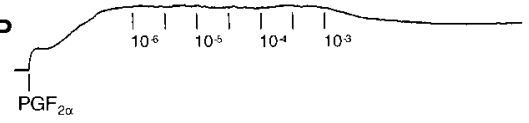

CP
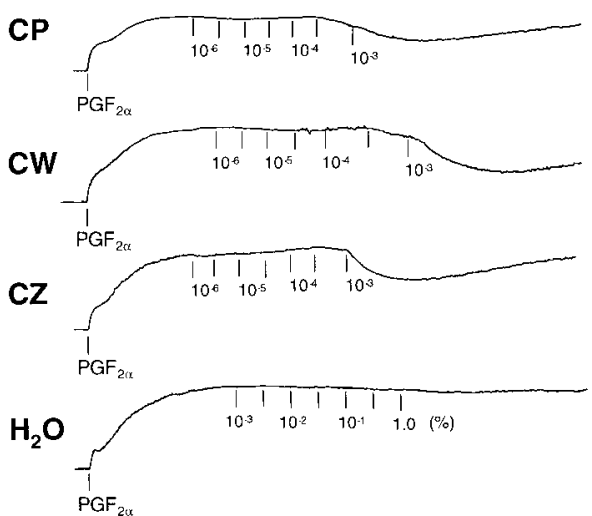

B

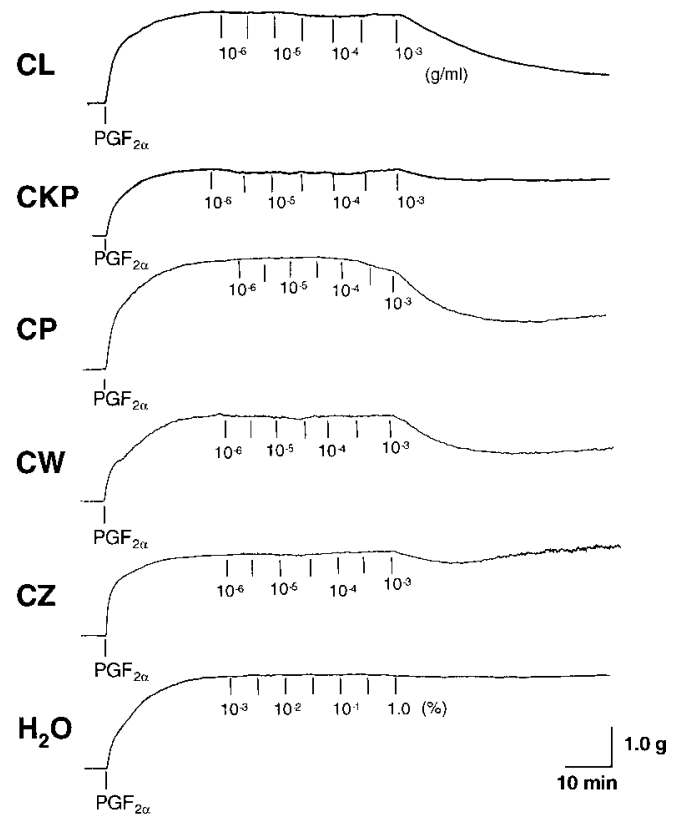

Fig. 1. Typical Tracings of Effects of Water Extracts on Isolated Rat Aorta Precontracted with $\mathrm{PGF}_{2 \alpha}$

The rings were pretreated with (A) only $\mathrm{PGF}_{2 \alpha}\left(6 \times 10^{-6} \mathrm{M}\right)$ or $(\mathrm{B}) \mathrm{PGF}_{2 \alpha}$ and L-NAME $\left(10^{-4} \mathrm{M}\right)$. Vehicle solution was water $\left(\mathrm{H}_{2} \mathrm{O}\right)$. Abbreviations are as follows: $\mathrm{CL}, \mathrm{C}$. longa; $\mathrm{CKP}$, C. kwangsiensis, C. phaeocaulis; $\mathrm{CP}$, C. phaeocaulis; CW, C. wenyujin; CZ, C. zedoaria. 
A

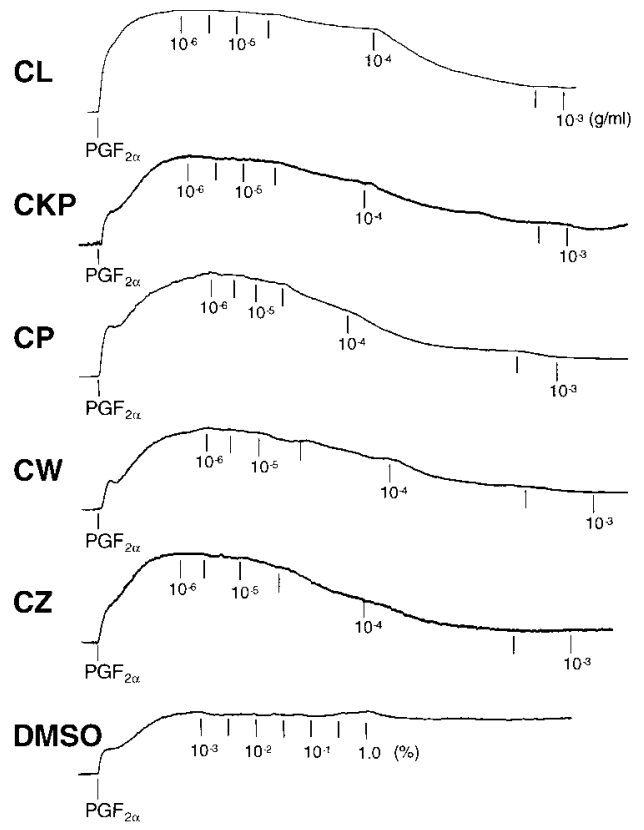

B

CL

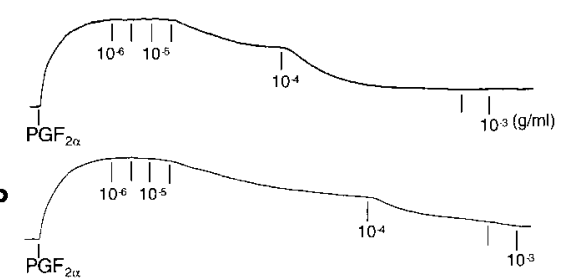

CP

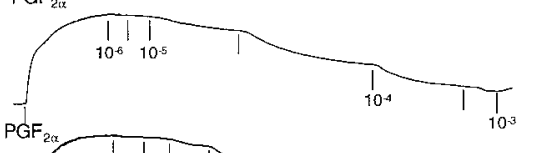

cW

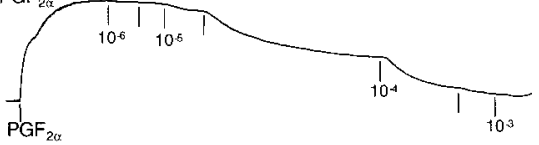

CZ

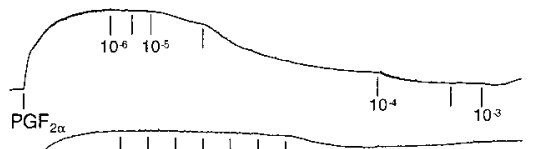

DMSO

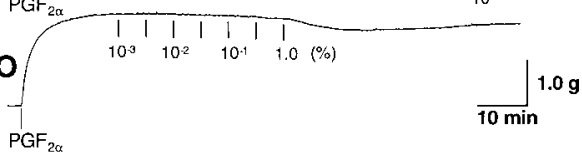

Fig. 2. Typical Tracings of Effects of Methanol Extracts on Isolated Rat Aorta Precontracted with PGF $2 \alpha$

The rings were pretreated with $(\mathrm{A})$ only $\mathrm{PGF}_{2 \alpha}\left(6 \times 10^{-6} \mathrm{M}\right)$ or $(\mathrm{B}) \mathrm{PGF}_{2 \alpha}$ and L-NAME $\left(10^{-4} \mathrm{M}\right)$. Vehicle solution was DMSO. Abbreviations same as in Fig. 1.

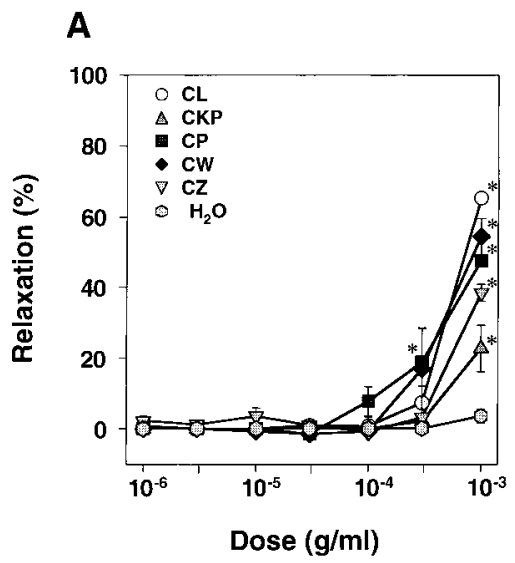

B

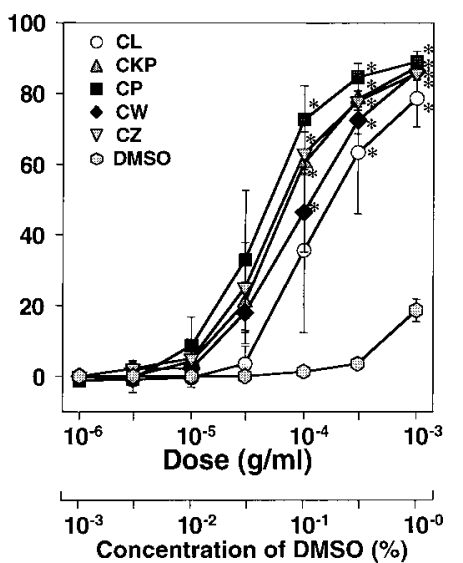

Fig. 3. Concentration-Response Curves for (A) Water Extracts or (B) Methanol Extracts-induced Relaxation in Rat Aortic Rings Precontracted with $\mathrm{PGF}_{2 \alpha}$

Vehicle solutions were water $\left(\mathrm{H}_{2} \mathrm{O}\right)$ and DMSO for water and methanol extracts, respectively. Values are expressed as percentage of decrease in the maximal tension contracted with $\mathrm{PGF}_{2 \alpha}\left(6 \times 10^{-6} \mathrm{M}\right)$. Results are shown as the mean \pm S.E. of 4 samples. $* p<0.05$ vs. vehicle. Abbreviations same as in Fig. 1.

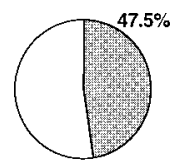

CL

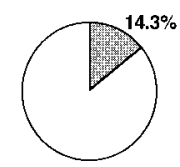

CKP

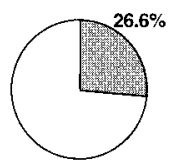

CP

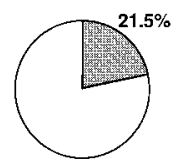

CW

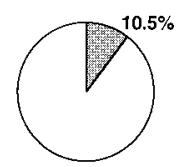

Cz

Fig. 4. The Percentages of Methanol-Soluble Compounds in Water Extracts

Closed and open regions show methanol-soluble and -insoluble parts in water extracts. Abbreviations same as in Fig. 1.

contraction: the contraction activities were $21.9 \%$ in CL, $11.3 \%$ in CKP, $47.8 \%$ in $\mathrm{CP}, 45.3 \%$ in $\mathrm{CW}$, and $36.3 \%$ in $\mathrm{CZ}$ at a concentration of $10^{-3} \mathrm{~g} / \mathrm{ml}$ (Fig. $5 \mathrm{~A}$ ).

Study on NO Involvement To learn whether the relaxation and contraction effects shown in Figs. 1A, 2A, and 5A were NO-dependent or -independent, L-NAME was pretreated to the rings to inhibit the synthesis of NO (Figs. 1B, $2 \mathrm{~B}, 5 \mathrm{~B})$. The water extract of $\mathrm{CZ}$ showed significant decrease in relaxation activity by pretreatment of L-NAME $(38.3 \rightarrow 13.2 \%)$, while the other four water extracts showed 
A

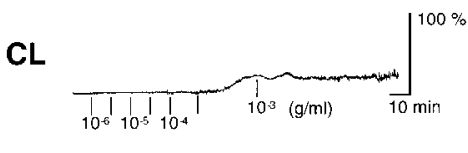

B

CL

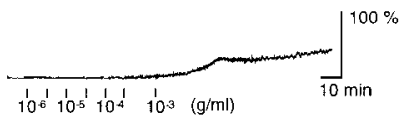

CKP

CP
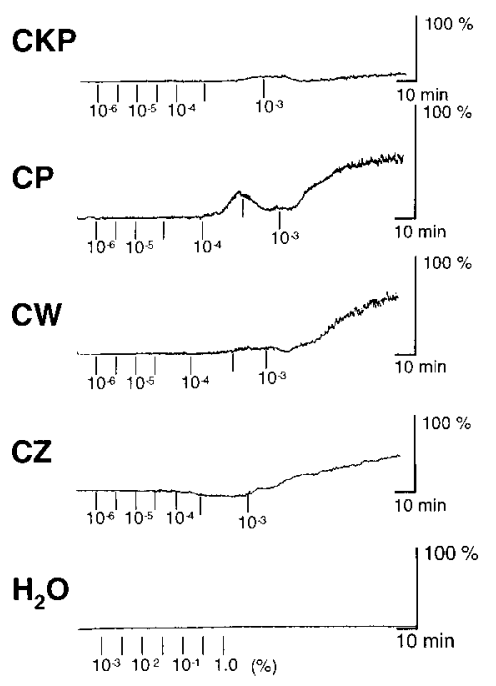

CZ

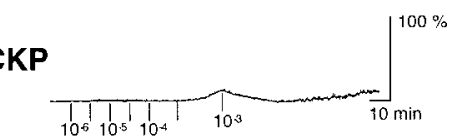

CP

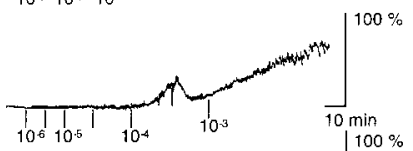

CW
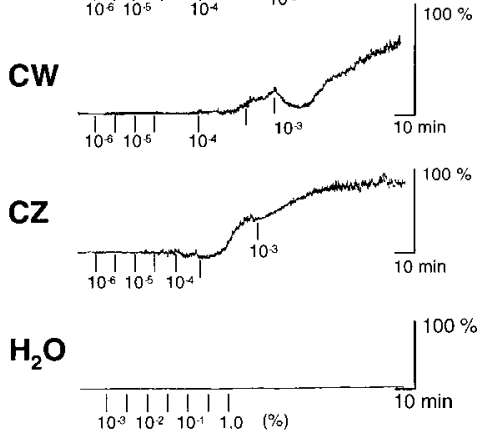

Fig. 5. Typical Tracings of Effects of Polysaccharides on Isolated Rat Aorta Precontracted with $\mathrm{PGF}_{2 \alpha}$

The rings were pretreated (B) with L-NAME $\left(10^{-4} \mathrm{M}\right)$ or $(A)$ without. Vehicle solution was water $\left(\mathrm{H}_{2} \mathrm{O}\right)$. Abbreviations same as in Fig. 1.

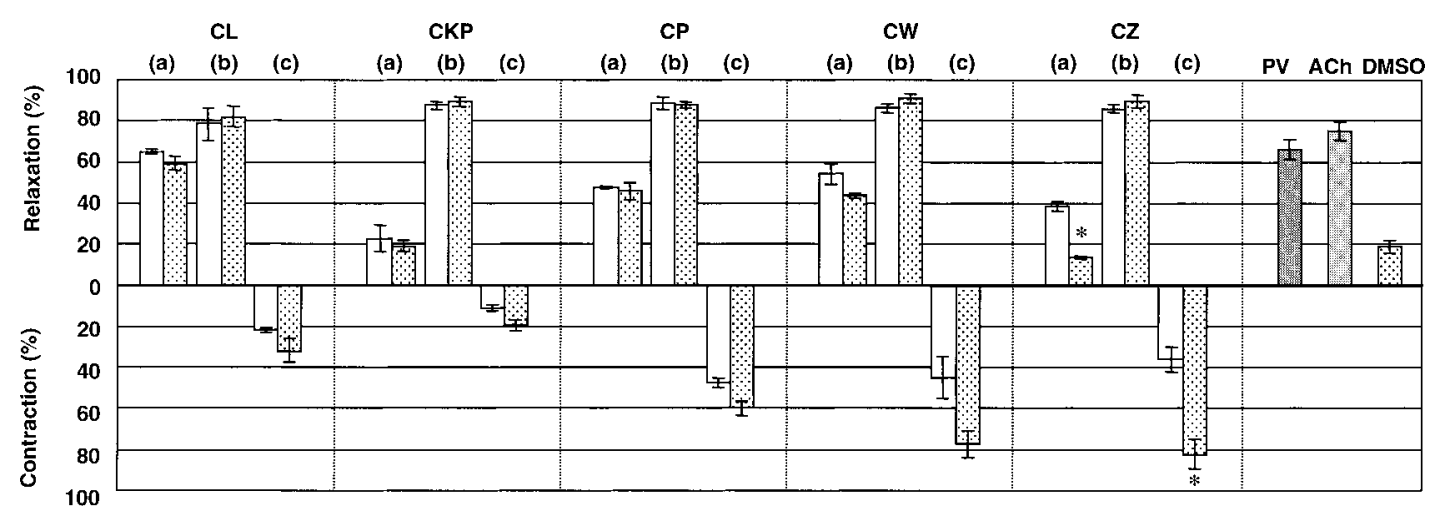

Fig. 6. Relaxation (Upper) and Contraction (Lower) Responses to (a) Water Extracts, (b) Methanol Extracts, and (c) Polysaccharides on Isolated Rat Aorta

Concentrations of extracts and polysaccharides were $10^{-3} \mathrm{~g} / \mathrm{ml}$. Rings were pretreated with (dotted columns) or without (open columns) L-NAME ( $10^{-4} \mathrm{M}$ ). For relaxation experiments, rings were precontracted with $\mathrm{PGF}_{2 \alpha}\left(6 \times 10^{-6} \mathrm{M}\right)$. Papaverine $\left(10^{-5} \mathrm{M}\right)$ and acetylcholine $\left(10^{-6} \mathrm{M}\right)$ were used as a positive control, and vehicle solution was water $($ water extract and polysaccharides) or DMSO (1.0\%, methanol extract). Results are shown as the mean \pm S.E. of 4 samples. $* p<0.05 v s$. without L-NAME. Abbreviations: PV, papaverine and ACh, acetylcholine; others same as in Fig. 1.

no differences with such pretreatment. Relaxation effects by methanol extracts were not affected by L-NAME treatment in any of the Curcuma drugs. On the other hand, polysaccharides from $\mathrm{CZ}$ showed significant increase in contraction effect (36.4 $\rightarrow 82.4 \%$ ) by L-NAME pretreatment (Fig. 6).

Relaxation Effects of Isolated Compounds From the methanol extracts of the five Curcuma drugs, major compounds were isolated, and their structures were determined by spectrometric analysis. One kind of curcuminoid (curcumin), three kinds of bisabolane-type sesquiterpenes ( $\alpha$ turmerone, $\beta$-turmerone and $a r$-turmerone), two kinds of furanogermacrane-type sesquiterpenes (furanodine and furanodienone), and three kinds of germacrane-type sesquiterpenes (curdione, germacrone and dehydrocurdione) were isolated (Chart 1). The relaxation experiments were conducted for these compounds and at the concentration from $10^{-7}$ to
$10^{-4} \mathrm{M}$ on rings pretreated with L-NAME (Fig. 7). Only furanodiene showed significant effects of relaxation from $10^{-5} \mathrm{M}$, and the mixture of $\alpha$-turmerone and $\beta$-turmerone, germacrone, and dehydrocurdione showed significant relaxation from $3 \times 10^{-4} \mathrm{M}$. The maximal activities were $76.9 \%$ in arturmerone, $79.1 \%$ in the mixture of $\alpha$-turmerone and $\beta$ turmerone, $71.4 \%$ in curcumin, $82.6 \%$ in furanodiene, $73.0 \%$ in furanodienone, $83.2 \%$ in germacrone, $59.8 \%$ in curdione, and $67.8 \%$ in dehydrocurdione at $10^{-3} \mathrm{M}$. Neither significant differences in relaxation activity nor a clear structure activity relationship was seen among compounds. Intensions of relaxation activities of isolated compounds without L-NAME treatment did not differ from those with L-NAME treatment (data not shown). 

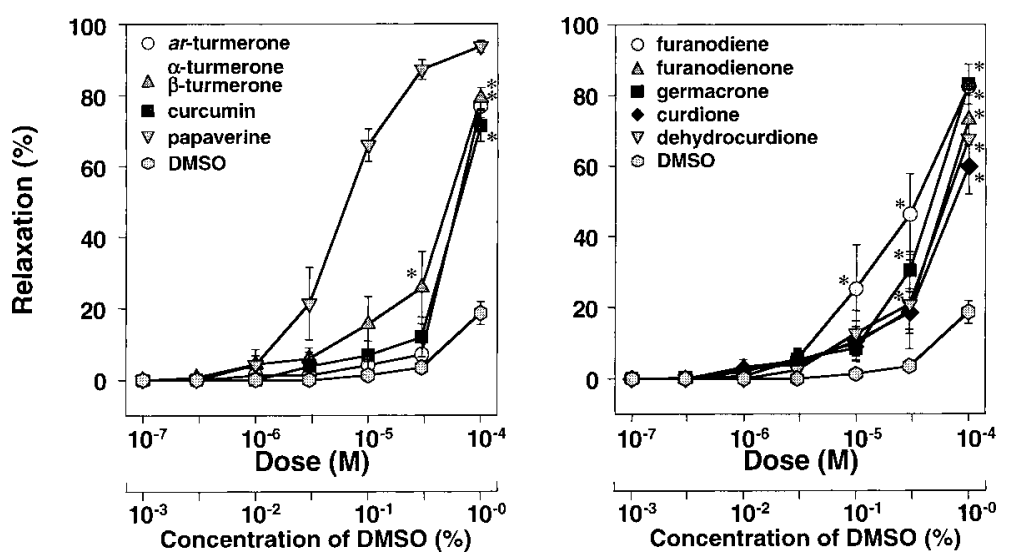

Fig. 7. Concentration-Response Curves for Isolated Compound-Induced Relaxation of Rat Aortic Rings Precontracted with PGF $_{2 \alpha}$

The rings were pretreated with $\mathrm{PGF}_{2 \alpha}\left(6 \times 10^{-6} \mathrm{M}\right)$ and L-NAME $\left(10^{-4} \mathrm{M}\right)$. Vehicle solutions were DMSO. Papaverine was used as a positive control. Values are expressed as percentage of decrease in the maximal tension contracted with $\mathrm{PGF}_{2 \alpha}$. Results are the mean \pm S.E. of 3 samples. $* p<0.05 v s$. vehicle.

A

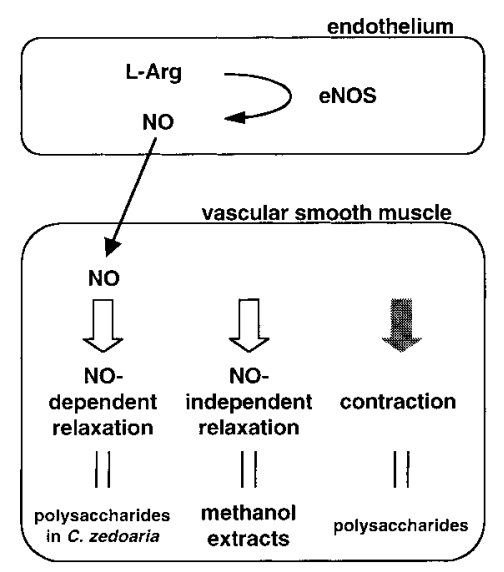

B

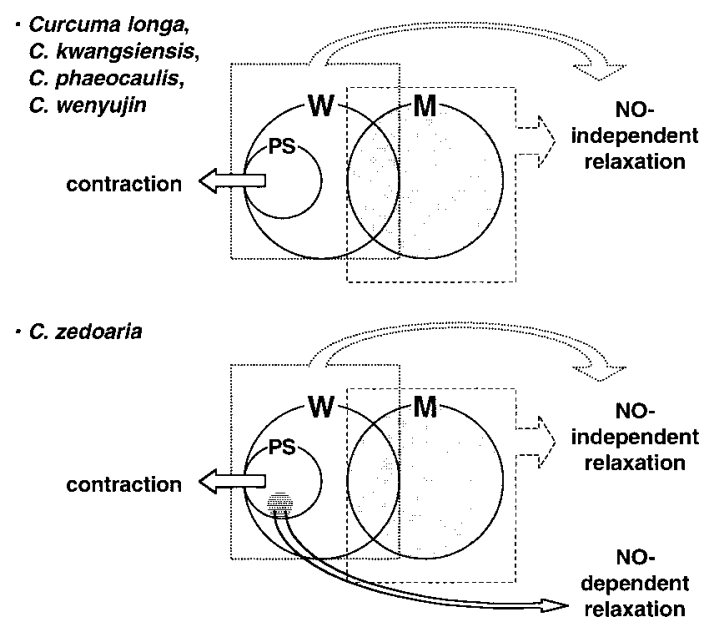

Fig. 8. Schematic Diagrams of Vasomotion Effects (A) and Inclusive Relations of Water and Methanol Extracts, and Polysaccharides (B) Abbreviations: L-Arg, L-arginine; eNOS, endothelial NO synthase; PS, polysaccharides; W, water extract; M, methanol extract.

\section{DISCUSSION}

We examined the vasomotional effects of water and methanol extracts and compounds from five Curcuma drugs which were identified correctly by molecular biological analysis. ${ }^{11)}$ The significant effects of relaxation induced by methanol extracts were found at more than $10^{-4} \mathrm{~g} / \mathrm{ml}$ except for $\mathrm{CL}$, and five of the methanol extracts showed intense relaxation effects, approximately $80 \%$, at $10^{-3} \mathrm{~g} / \mathrm{ml}$. The relaxation effects of water extracts were lower than those of methanol extracts, and the intensities of effects at $10^{-3} \mathrm{~g} / \mathrm{ml}$ were different depending on the Curcuma drug; they were high in the order CL, CW, CP, CZ, and CKP. Since it seemed that methanol-soluble compounds were also partly involved in water extracts, percentages of methanol-soluble fractions in these extracts were measured. The methanol-soluble fraction was high in the order CL, CP, CW, CKP, and CZ, suggesting that the greater the content of methanol-soluble compounds, the stronger could be the effects of relaxation expected. These results indicated that the relaxation effects of Curcuma drugs were mostly due to methanol-soluble compounds.
Polysaccharides are the main constituents in methanol-insoluble fractions, and therefore are necessarily contained in water extracts. Our result showed that polysaccharides had contraction effects.

In all five Curcuma drugs, relaxation effects by water extracts were due to the sum of methanol-soluble compoundsinduced relaxation and polysaccharides-induced contraction. In pretreatment with L-NAME, however, only $\mathrm{CZ}$ showed different aspects of reactions. The water extract-induced relaxation was decreased $66.0 \%$ by L-NAME, while polysaccharides-induced contraction was increased $55.8 \%$ by LNAME. These indicate that $\mathrm{CZ}$ contains some polysaccharides which induce relaxation by promoting NO production. Although CZ seems to contain polysaccharides with an opposite effect on the vasomotion, it is unknown yet what they are.

It is known that relaxation of vascular smooth muscles is induced by prostaglandin $\mathrm{I}_{2}, \mathrm{Ca}^{2+}$ antagonists, $\alpha$-blocker, $\beta$ blocker, ${ }^{22)}$ in addition to NO. ${ }^{9}$ Our present results clarified that $\mathrm{CZ}$ contained not only the components in the methanol soluble fraction for relaxation through the NO-independent pathway but also other components in the polysaccharide 
fraction for relaxation through the NO-dependent pathway, while, the four other Curcuma drugs contained only the components for relaxation through NO-independent pathway in the methanol soluble fraction (Fig. 8). The contraction effect induced by polysaccharides in $\mathrm{CZ}$ was increased in the rings without endothelium (data not shown). This increase in activity was also seen in intact rings with endothelium pretreated with L-NAME. These results suggest polysaccharides in $\mathrm{CZ}$ may be enhancing NO production evoked by endothelial NO synthase (eNOS) in endothelium cells, although they do not affect vascular smooth muscles.

It is known that contraction of vascular smooth muscles is induced by endothelin, prostaglandin $\mathrm{F}_{2 \alpha}$, adrenergic $\alpha$-agonist, angiotensin II, and so on. ${ }^{22)}$ The contraction effects must also play an important role in blood vessels in the balance with relaxation. The mechanisms of contraction induced by polysaccharides of the five drugs have not yet been identified. Polysaccharides in nature are of numerous varieties, and are different in molecular weight, sugar constituents, position of linkage, and type of linkage of sugars. Although some of them have pharmacological activities like antitumor ${ }^{23)}$ and immunological activity, ${ }^{3}$ it is not clear whether polysaccharides are absorbed from intestine or not.

We isolated curcumin and eight kinds of sesquiterpenes from five Curcuma drugs and examined the vasomotional effects. Although each compound induced intense relaxation effects, we could find no clear structure-activity relationships among them. All these relaxation effects by isolated compounds were thought to be induced NO-independently, because almost the same results were obtained on the rings pretreated both with and without L-NAME. The sesquiterpenes, which are main components of essential oil together with monoterpenes, showed the same aspects of relaxation effects despite differences among structures, suggesting that the total amount of essential oil may be one index for the estimation of relaxation effects. Gajutsu from C. zedoaria is described to contain more than $0.5 \mathrm{ml}$ of volatile oil in $50 \mathrm{~g}$ in the Japanese Pharmacopoeia. ${ }^{24)}$ This may be a reasonable standard value from the point of view of anti-Oketsu drugs.

CL contained a rich amount of curcumin (ca. 1.8\%, our unpublished data analyzed by HPLC) and CP also contained a small amount (ca. $0.1 \%$ ). Since there are many reports about pharmacological activities like anti-inflammatory, ${ }^{25}$ ) free-radical scavenging activity, ${ }^{26)}$ or antihepatotoxic activity ${ }^{27)}$ in addition to these vasodilator effects, CL may be especially useful for Oketsu supervened with an inflammatory disease.

Oketsu is defined as "the state in which the blood is, for some reason, static and does not flow smoothly."28) These states are seen in various diseases like hypertension, arteriosclerosis, or menopausal syndrome. It is reported that $\mathrm{NO}$ production in endothelium is decreased in arteriosclerosis, ${ }^{29)}$ and that endothelium dependent vasodilation is effective for hypertension. ${ }^{30)}$ These reports showed that NO production in blood vessels, especially in endothelium, is effective to improve blood flow. That is, the relaxation through the NO-dependent pathway is induced by the increase of NO in endothelium. As $\mathrm{CZ}$ was the only drug to show NO-dependent relaxation among the five Curcuma drugs, CZ may be expected to cure Oketsu from various acting points. Although we proved the anti-Oketsu effects of Curcuma drugs by their vasomotional effects on isolated rat aorta, in vivo experiments such as vasomotion of blood capillary and blood rheology should be studied further to confirm usefulness of the drugs.

Although several Curcuma drugs are used with discrimination as anti-Oketsu substances, the true pharmacological differences among them have been obscure. In this study, the differences of relaxation effects among five Curcuma drugs, CL called "Ukon" and CW, CP, CKP and CZ called "Gajutsu" in Japanese, were demonstrated. Each compound isolated from methanol extracts had intense effect on relaxation in rings pretreated by $\mathrm{PGF}_{2 \alpha}$. Therefore, the vasodilator abilities of Curcuma drugs can be estimated from the total amounts of methanol-soluble compounds, such as curcumin and essential oil. Moreover, since the water extracts of only CZ showed NO-dependent relaxation, in addition to NO-independent relaxation which was common to the other 4 drugs, this drug is thought to be more effective against Oketsu.

Acknowledgements This work was supported in part by a Grant-in-Aid for Scientific Research (B) No. 11695086 in 1999-2001 and No. 14406030 in 2002 from the Japan Society for the Promotion of Science.

\section{REFERENCES}

1) Khar A., Ali A. M., Pardhasaradhi B. V. V., Begum Z., Anjum R., FEBS Lett., 445, 165-168 (1999).

2) Ozaki Y., Chem. Pharm. Bull., 38, 1045-1048 (1990).

3) Gonda R., Tomoda M., Ohara N., Takada K., Biol. Pharm. Bull., 16, 235-238 (1993).

4) Li S. Z., "Ben-cao gang-mu," Jiangxi ed., Vol. 2, The People's Health Pub. House, Beijing, 1977, pp. 880-885.

5) Terasawa K., Kimura M., Sakuragawa N., Uchiyama Y., Toriizuka K., Ueno M., Horikoshi I., Yakugaku Zasshi, 103, 313-318 (1983).

6) Tanikawa K., Goto H., Nakamura N., Tanaka N., Hattori M., Itoh T., Terasawa K., J. Trad. Med., 16, 45-50 (1999).

7) Kosuge T., Ishida H., Yamazaki H., Chem. Pharm. Bull., 33, 14991502 (1985).

8) Irie K., Yoshioka T., Nakai A., Ochiai K., Nishikori T., Wu G. R., Shibuya H., Muraki T., Eur. J. Pharmacol., 403, 235-242 (2000).

9) Palmer R. M. J., Ferrige A. G., Moncada S., Nature (London), 327, 524-526 (1987).

10) Nguyen B. L., Saitoh M., Ware J. A., Am. J. Physiol., 261, H1043H1052 (1991).

11) Sasaki Y., Fushimi H., Cao H., Cai S. Q., Komatsu K., Biol. Pharm. Bull., 25, 1593-1599 (2002).

12) George M. S., Li Y., Can. J. Chem., 70, 1317-1322 (1997).

13) Bernard T. G., Esteban P. V., J. Chem. Soc. Perkin Trans. I, 1992, $1519-1524$ (1992).

14) Kiuchi F., Goto Y., Sugimoto N., Akao N., Kondo K., Tsuda Y., Chem. Pharm. Bull., 41, 1640-1643 (1993).

15) Hikino H., Agatsuma K., Konno C., Takemoto T., Chem. Pharm. Bull., 18, 752-755 (1970).

16) Hikino H., Konno C., Agatsuma K., Takemoto T., Horibe I., Tori K., Ueyama M., Takeda K., J. Chem. Soc. Perkin Trans. I, 1974, 478-484 (1974).

17) Hikino H., Sakurai Y., Takahashi H., Takemoto T., Chem. Pharm. Bull., 15, 1390-1394 (1967).

18) Inayama S., Gao J. F., Harimaya K., Iitaka Y., Guo Y. T., Kawamata T., Chem. Pharm. Bull., 33, 1323-1326 (1985).

19) Takahashi T., Kitamura K., Nemoto H., Tsuji J., Miura I., Tetrahedron Lett., 24, 3489-3492 (1983).

20) Hikino H., Konno C., Takemoto T., Chem. Pharm. Bull., 20, 987-989 (1972).

21) Goto H., Shimada Y., Akechi Y., Kohta K., Hattori M., Terasawa K., Planta Medica, 62, 436-439 (1996). 
22) Luscher T. F., Boulanger C. M., Dohi Y., Yang Z., Hypertension, 19, 27) Kiso Y., Suzuki Y., Watanabe N., Oshima Y., Hikino H., Planta Med$117-130$ (1992).

23) Ohno N., Miura N. N., Nakajima M., Yadomae T., Biol. Pharm. Bull. 23, 866-872 (2000).

28) Kohta K., Hiyama Y., Terasawa K., Hamazaki T., Itoh T., Tosa H., J. Trad. Med., 9, 221-228 (1992).

24) Ministry of Health, Labour and Welfare (ed.), "The Japanese Pharmacopoeia (14th ed.)," Tokyo, 2001, p. 831.

25) Dirsch V. M., Stuppner H., Vollmer A. M., Planta Medica, 64, 423426 (1998).

29) Hirata K., Akita H., Inoue N., Matsuda Y., Yokoyama M., Jpn. Circ. J., 56, 1308-1313 (1992).

26) Elizabeth K., Rao M. N. A., Int. J. Pharm., 58, 237-240 (1990).

30) Goto H., Shimada Y., Tanigawa K., Sekiya N., Shintani T., Terasawa K., Am. J. Chin. Med., 27, 339-345 (1999). 